\title{
PROSPECTS TOWARDS \\ PROTECTING PUBLICLY ACCESSED COMPUTER SYSTEMS FROM INTENTIONAL EMI
}

\author{
Achyuta Nand Mishra ${ }^{1}$ and Prof. Dr. Sudan Jha ${ }^{2}$
}

\begin{abstract}
This paper introduces electromagnetic compatibility (EMC) as an integral process needed for the design of devices that are used in the operation of the Smart Grid. The report examines EMC issues for Smart Grid equipment on both the electric power system delivery and the power customer sides of the Smart Grid meter and summarizes recommendations for EMC standards. It is intended as a guide to apply documented EMC principles to better ensure the operation and interoperability1 of the Smart Grid in its intended electromagnetic (EM) environments. The general recommendations that follow come from the analysis of Smart Grid issues and standards. The reliable delivery of electric power to customers is the most obvious measure of how well a power grid is performing. The Smart Grid has the potential to improve the reliability of power delivery in many ways. But due to its increased complexity and reliance on technologies not previously incorporated into the grid, the Smart Grid also may be susceptible to factors that can negatively impact the reliability of power delivery. Some of these factors result from electromagnetic interference (EMI). EMC is defined as "the capability of electrical and electronic systems, equipment, and devices to operate in their intended electromagnetic environment within a defined margin of safety, and at design levels of performance without suffering or causing unacceptable degradation as a result of electromagnetic interference." So for a device, equipment, or system to be compatible it must be immune (or at least tolerant) to the EM disturbances that exist in its environment and not introduce additional disturbances. This implies that it will coexist and interoperate as designed with other systems in its environment.
\end{abstract}

Keywords: Electromagnetic compatibility, Smart Grid, Issues and Standards Smart Grid, Electromagnetic Interference.

\section{INTRODUCTION}

EMC may also be a factor in functional safety depending on the consequences of a failure due to electromagnetic interference (EMI). A high degree of EMC minimizes possible safety and performance failures due to EMI. EMC is also related to electric power quality in terms of the level of certain EM disturbances that may exist in the environment. Many of the interference phenomena or disturbances discussed in this paper can be related to power quality (i.e. power line harmonics, voltage surge, etc.). However, other than to recommend good installation and suppression practices, the EMII WG did not address the cause or control of these power quality issues, concentrating instead on the immunity requirements needed to be compatible with a given level of EM disturbances.

Smart Grid devices (e.g. microprocessor-based systems, communications devices, plug-in electric vehicle chargers, etc.) may also generate incidental electromagnetic emissions that could cause harmful interference to nearby electronic devices. The allowable emissions are limited by various national and international authorities at sufficiently low levels to minimize possible interference to other systems. Many of these regulations are based on consensus standards developed by Standards Development Organizations (SDOs) like ANSI [2], IEEE [3] and IEC/CISPR [4]. Hence, with the assumption that all

\footnotetext{
${ }^{1}$ Dr. KN Modi Univerity, Newai, Rajasthan, India

${ }^{2}$ School of Computer Engineering Kalinga Institute of Industrial Technology, KIIT University Bhubaneswar - 751024, Odisha, India
} 
electronic equipment will meet regulatory emissions limits, the scope of this paper includes only the immunity of Smart Grid systems and devices to the possible external electromagnetic interference impinging on this equipment.

In addition, the electromagnetic environments resulting from communications devices, and from typical transmitters in common use and not a part of Smart Grid devices and power customers, are assumed to generate EM fields well below human exposure limits that protect against adverse effects in humans. These limits, in terms of electric and magnetic field strength and power density, ensure that the exposure does not exceed the basic restrictions on which contemporary radio frequency safety standards. These standards are stated in terms of specific absorption rate (SAR), the rate of energy absorbed into human tissue per unit mass. Hence possible electromagnetic hazards to humans are not within the scope of this report. The focus remains on the electromagnetic immunity of Smart Grid devices and the Smart Grid infrastructure.

\section{RESEARCH OBJECTIVES - Electromagnetic COMPATIBILITY AND THE SMART GRID}

EMC must be considered to ensure continuous reliable real time operation in the many locations where the Smart Grid equipment will operate. Components and devices in the Smart Grid system are subjected to a wide range of conducted and radiated noise sources that are disruptive to all electronic systems (Smart Grid systems included). These sources can be categorized as follows:

- $\quad$ Conducted noise from such sources as power line harmonics, surge (from lightning and power system switching transients), and fast transients/bursts (interruption of inductive dc circuits)

- $\quad$ Radiated noise or signals from known transmitters (AM, FM, and TV broadcast transmitters, communications radios, wireless devices, etc.)

- High power events such as geomagnetic storms, intentional EM interference (IEMI) from portable transmitters, and EM pulses associated with high altitude nuclear detonation (HEMP).

- $\quad$ Electrostatic discharge events when a statically charged body (human or inert) comes in contact with a Smart Grid device.

Presently, for most equipment sold in Nepal and her surrounding states, there is no regulatory mandate that a manufacturer's product meet any immunity specification as immunity is considered a quality issue. Hence immunity considerations are left to the manufacturer and the purchaser to determine how much immunity is needed to work properly and to avoid recalls or in-field repairs. Thus many electric utilities include specific requirements in their purchase specifications for equipment such as protective relays, power station and substation apparatus, and kilowatt-hour meters (including Smart Meters). This is done by requiring compliance with specific IEEE, ANSI, or IEC standards. As a result, most manufacturers of products for the electric utility industry design them to meet specific standards - such as the IEEE C37.90 series for protective relays [10, 11, 12, 13], IEEE 1613 for communications networking devices [14], and ANSI C12.1 for kilowatt-hour meters, including Smart Meters [15]. The situation is different in other countries; they require products to meet the EMC Directive 2004/108/EC [16]. This directive requires both emissions and immunity conformance. Meeting harmonized standards [17] presumes compliance to the EMC Directive although other means of demonstrating such conformity are permitted. In general, manufacturers address specific EMC requirements for each country or region in their intended market.

\section{RECOMMENDATIONS FOR EMC STANDARDS AND TESTING}

A prerequisite for achieving electromagnetic compatibility between an electronic device and the electromagnetic environment and events that may cause interference is to quantify the environment. A clear understanding of the possible interference phenomena is necessary to design the most cost-effective device that is immune to the interference. However, it is difficult to determine the actual environment in every location the device may be installed so a "typical" or in some critical situations a "worst case" picture of the interference potential may have to guide the design. The starting point, therefore, is to determine if current EMC standards are adequate for the Smart Grid was to define the electromagnetic environments where Smart Grid devices may be installed. The result details a list of distinct environments that span the electric power grid from bulk generation to residential use. These environments each have particular characteristics that may warrant specific equipment design features in order to meet EMC requirements. Sources of possible interference in each of these environments are identified and several applicable EMC standards that may address the interference to Smart Grid devices are presented.

The EM environments at customer locations (residential, commercial, and industrial), are highly variable and, in many instances, they are unpredictable too. These environments may contain any number of interference sources in various densities and intensities ranging from very low in a remote single family home (for example) to extremely noisy in a dense industrial location (similar to a power substation). One method to characterize these locations is to assemble an inventory of known interference sources and map the expected intensity at a Electromagnetic Compatibility and Smart Grid Interoperability Issues "typical" residential, commercial, or industrial location. The electromagnetic environments within the electric utility system (generation, distribution, substations, etc.), while more severe than the customer locations, are generally more predictable and better quantified. However, the information in IEC/TR 61000-2-5 ed.2 [19] does not generally apply to electric utility environments (except possibly some of the industrial environments wherein utility control facilities may be located) so applicable product EMC standards intended for these locations were examined directly. 
If a Smart Grid device is to be installed at more than one of these environments, a decision has to be made as to which environment is the most likely. Investigation of the noise source levels in the industrial environment generally indicate the highest level of potential interference to Smart Grid devices and require a corresponding high level of immunity and test levels. If however, the likelihood is far greater that the device will be located in the residential and/or commercial environment, then the highest immunity level may not be appropriate. It is also noted that expected level of interference in IEC/TR 61000-2-5 [19] may be the same for two of the three environments. This, of course, reduces the number of possible immunity test levels to select and thus implies that the two environments are similar for those particular RF phenomena. If on the other hand, the Smart Grid device or system is installed in all locations, then it must be designed to withstand the most severe environments (e.g. power substation).

Lightning is a common event that effects local sections of the grid but can strike anywhere. The installation of proper grounding, surge protection, and equipment designed to tolerate moderate levels of electrical surges are all necessary to protect equipment against lightning events. Some events plague large areas of the power grid simultaneously such as geomagnetic storms or high power pulses.

IEMI is a more localized (and more likely) threat that can also cause serious problems to unprotected facilities. The technical basis for providing a level of immunity to these events is discussed in Appendix B along with standards development organizations currently addressing these high power events.

The EMII WG firmly believes that the first level of HPEM protection begins with a solid EMC program and robust Smart Grid immunity to the typical EM interference events. The application of protective measures for high power events then builds on the immunity at the equipment level. The EMII WG recommends that the standards cited in Appendix B be considered when selecting equipment for critical Smart Grid applications. Ultimately, protecting the electric grid from these high power events requires a coordinated effort between the utilities, regulators, and policy makers. That discussion is beyond the scope of this report. The decision is up to the manufacturer and those that specify requirements such as electric power utilities or regulators. Once the immunity requirements are set, the manufacturer can then design and test to those levels. These requirements and associated performance criteria may also form the basis for a possible immunity compliance testing program performed by certified manufacturers or third party test/compliance laboratories.

\section{WORK DETAIL \& RECOMMENDATIONS}

Based on the above arguments, we recommend that all Smart Grid equipment should be designed to ensure electromagnetic compatibility to its intended operational environment and, in particular, immunity to electromagnetic interference. This can be accomplished by the following:

1. Manufacturers should design Smart Grid products for EM immunity to at least the disturbance levels in IEC 61000-2-5 [19] for customer environments.

2. Manufacturers should design equipment for electric power utility environments to levels specified by the IEEE C37.90 [10 - 13] series for protective relays, ANSI C12.1 [15] for kilowatt-hour meters and IEEE 1613 for communications networking devices. Immunity tests in IEC 61850-3

3. Devices must be designed to meet emissions requirements as per national regulations (e.g. FCC or EU).

4. Adequate EMC should be verified by testing using established IEEE, IEC, or other standard test methods. The testing may be accomplished by the manufacturer or, if appropriate, by an accredited third-party test laboratory.

5. For installations on the customer side of the Smart Meter, reduce adverse EM exposure by appropriate installation practices and suppression of disturbance levels.

There are likely to be EM interference and compatibility issues to be addressed as new technology and systems are introduced into the Smart Grid. Many of these EMC issues may be addressed through an update of established IEEE, IEC, or other standards while others may require new standards specifically tailored to the technology and the application. This is, of course, the primary task of SDOs. The IEEE and IEC have both organized working groups to provide guidance to their various EMC committees with regards to Smart Grid standards. The SGIP and the EMII WG are in a unique position to track the development of Smart Grid technology and progression of EMC standards, and to provide a forum for all the stakeholders to address possible EMC issues and recommend further standards development. 


\section{RESUlTS AND DiscusSiON}

The steady growth and changes to Smart Grid technology will necessitate a dynamic strategy to maintain EMC and reliable operation. All players in the Smart Grid (manufacturers, utilities, standards development organizations, government, and customers) have a role in maintaining a robust and reliable grid control system. The following identifies actions in these entities:

1. Manufacturers: design and test products to demonstrate EM immunity per specific standards.

2. Utilities: Continue to specify that components for the smart grid meet the EMC requirements in specific standards. Utilities may require additional compliance testing.

3. Electric power customers (especially commercial and industrial): Practice good installation procedures and specify products that have good EMC design.

4. SDOs: Continue to develop and update EMC standards where found necessary to reflect the progress in technology and the Smart Grid electromagnetic environments.

5. Government: Evaluate national policies and priorities for protection of the electric power infrastructure from electromagnetic interference, especially high-power events like HEMP, IEMI, and geomagnetic storms.

The only way to know how well a device will perform in the presence of electromagnetic interference is to expose the device to similar phenomena in a controlled test. Conformity to any particular EMC standard should be verified through testing by the manufacturer at the design and development stage and/or later using production samples. These tests should be performed in accredited laboratories (either in-house by the manufacturer/utilities or by third-party test laboratories). In addition a quality program should be applied based on the competency of laboratories to determine if Smart Grid devices are compliant. Adherence to ISO/IEC 17025 [26] (with specific additional requirements for Smart Grid application) is a wellrecognized method to show test laboratory competency. However this does not preclude the use of test labs, including those of the manufacturer/utility, that are not compliant with ISO/IEC 17025.

Electromagnetic compatibility and electromagnetic immunity are topics that affect the entire operation of the grid and as such the work described in this document is complementary to many other efforts within the SGIP. For example, the Hometo-Grid (H2G) Domain Expert Working Group (DEWG) has clearly identified the need for electromagnetic compatibility in SG devices used in the home environment as described in the H2G DEWG report (Electromagnetic Compatibility (EMC) Issues for Home-to-Grid Devices). It should be noted that an installation guidance document is also part of $\mathrm{H} 2 \mathrm{G}$ activity in cooperation with the Consumer Electronics Association [27]. They provide information on electrical installation techniques that will reduce the exposure of consumer electronic equipment to power line surge and other sources of interference.

\section{CONCLUSION}

This paper provides recommendations to improve the ability of Smart Grid devices to interoperate as intended and survive the electromagnetic environment that exists in such locations as those associated with residential, commercial and industrial environments. It is important that EMC be designed into all components/devices that comprise the Smart Grid control system so that reliability is better assured. There is no guarantee that all Smart Grid devices will tolerate all such EMC environments, but without taking into consideration EMC the probability of the system failing to operate as intended increases significantly. Good EMC practices combined with the EMC design test levels indicated in this report and the referenced standards should be used to significantly increase the probability that the Smart Grid system will work and withstand the disturbances caused by the EM environment.

\section{REFERENCES}

[1] ANSI C63.14-2009: American National Standard Dictionary of Electromagnetic Compatibility (EMC) including Electromagnetic Environmental Effects (E3), Accredited Standards Committee C63®, Institute of Electrical and Electronics Engineers, New York, NY. http://ieeexplore.ieee.org/xpl/mostRecentIssue.jsp?punumber=5291660

[2] http://www.ansi.org/

[3] http://www.ieee.org/index.html

[4] http://www.iec.ch/index.htm

[5] IEEE C95.1-2005, IEEE Standard for Safety Levels with Respect to Human Exposure to Radio Frequency Electromagnetic Fields, $3 \mathrm{kHz}$ to $300 \mathrm{GHz}$, Institute of Electrical and Electronics Engineers, New York, NY

[6] IEEE C95.6-2002 (R2007), IEEE Standard for Safety Levels with Respect to Human Exposure to Electromagnetic Fields, 0-3 kHz, Institute of Electrical and Electronics Engineers, New York, NY.

[7] ICNIRP, Guidelines for Limiting Exposure to Time-varying Electric, Magnetic and Electromagnetic Fields, (up to 300 GHz), Health Physics, vol. 74, no. 4, pp. 494 - 522, International Commission on Non-Ionizing Radiation Protection, 1998.

[8] ICNIRP, Guidelines for Limiting Exposure to Time-varying Electric and Magnetic Fields (1 Hz to $100 \mathrm{kHz})$, Health Physics, vol. 99, no. 6, pp. 818 - 836, International Commission on Non-Ionizing Radiation Protection, 2010.

[9] EN 62209-1:2006, Human exposure to radio frequency fields from hand-held and body-mounted wireless communication devices Human models, instrumentation, and procedures - Part 1: Procedure to determine the specific absorption rate (SAR) for hand-held devices used in close proximity to the ear (frequency range of $300 \mathrm{MHz}$ to $3 \mathrm{GHz}$ ), CEN-CENELEC, 17, Avenue Marnix B-1000 Brussels; http://www.cenelec.eu/dyn/www/f?p=104:110:6404768608765346::::FSP_PR OJECT,FSP_LANG_ID:15912,25

[10] C37.90-2005 - IEEE Standard for Relays and Relay Systems Associated with Electric Power Apparatus, http://ieeexplore.ieee.org/servlet/opac?punumber=10595

[11] C37.90.1-2002 - IEEE Standard for Surge Withstand Capability (SWC) Tests for Relays and Relay Systems Associated With Electric Power Apparatus, http://ieeexplore.ieee.org/servlet/opac?punumber=7894 
[12] C37.90.2-2004 - IEEE Standard for Withstand Capability of Relay Systems to Radiated Electromagnetic Interference from Transceivers, http://ieeexplore.ieee.org/servlet/opac?punumber=9482

[13] C37.90.3 - $2001 \quad$ - $\quad$ IEEE Standard Electrostatic Discharge Tests for Protective Relays, http://ieeexplore.ieee.org/servlet/opac?punumber=7615

[14] IEEE 1613 - 2009 - IEEE Standard Environmental and Testing Requirements for Communications Networking Devices Installed in Electric Power Substations, http://ieeexplore.ieee.org/servlet/opac?punumber=5233391

[15] NEMA / ANSI C12.1 - 2008, Electric Meters Code for Electricity Metering, American National Standards Institute, Washington DC, http://webstore.ansi.org/RecordDetail.aspx?sku=ANSI+C12.1-2008\#.UG7381Eeq38

[16] http://ec.europa.eu/enterprise/sectors/electrical/emc/

[17] http://ec.europa.eu/enterprise/policies/european-standards/documents/harmonised-standards-legislation/listreferences/electromagnetic-compatibility/index_en.htm

[18] IEC Technical Committee 77 website: http://www.iec.ch/dyn/www/f?p=103:7:0::::FSP_ORG_ID:1265

[19] IEC/TR 61000-2-5 ed2.0, Electromagnetic compatibility (EMC) - Part 2-5: Environment - Description and classifications of electromagnetic environments, International Electrotechnical Commission, Geneva, Switzerland. http://webstore.iec.ch/Webstore/webstore.nsf/Artnum_PK/45165

[20] IEC/CISPR 24 ed2.0, Information technology equipment - Immunity characteristics - Limits and methods of measurement, International Electrotechnical Commission, Geneva, Switzerland. http://webstore.iec.ch/Webstore/webstore.nsf/ArtNum_PK/44481?OpenDocu ment

[21] IEC 61326 series, Electrical equipment for measurement, control and laboratory use - EMC requirements, International Electrotechnical Commission, Geneva, Switzerland. http://webstore.iec.ch/Webstore/webstore.nsf/mysearchajax?Openform\&key= $61326 \&$ sorting $=\&$ start $=1$ \&onglet $=1$

[22] IEC 61850-3 ed1.0, Communications networks and systems in substations - Part 3: General requirements, International Electrotechnical Commission, Geneva, Switzerland. http://webstore.iec.ch/webstore/webstore.nsf/ArtNum_PK/28400

[23] IEC 60255-26, Measuring relays and protection equipment - Part 26: Electromagnetic compatibility requirements, International ElectrotechnicalCommission, Geneva, Switzerland. http://webstore.iec.ch/webstore/webstore.nsf/Artnum_PK/41734

[24] IEC/TS 61000-6-5 ed1.0 - Electromagnetic compatibility (EMC) - Part 6-5: Generic standards - Immunity for power station and substation environments, International Electrotechnical Commission, Geneva, Switzerland. http://webstore.iec.ch/Webstore/webstore.nsf/ArtNum_PK/27423?OpenDocu ment

[25] IEC 61000-4-xx series, Electromagnetic compatibility (EMC) - Part 4-xx: Testing and measurement techniques - (various test methods), International Electrotechnical Commission, Geneva, http://webstore.iec.ch/Webstore/webstore.nsf/mysearchajax?Openform\&key=61000-4\&sorting=\&start=1\&onglet=1

[26] ISO/IEC 17025:2005, General requirements for the competence of testing and calibration laboratories. International Organization for Standardization, Geneva, Switzerland. http://www.iso.org/iso/catalogue_detail?csnumber=39883

[27] CEA/CEDIA-CEB29, Recommended Practice for the Installation of Smart Grid Devices, Consumer Electronics Association (CEA), Arlington, VA. http://www.techstreet.com/cgi-bin/detail?doc_no=cea|ceb29;product_id=1829125. 